\title{
Bjomédica
}

\section{El Microbioma y las enfermedades neurodegenerativas del Sistema Nervioso Central}

Juan Carlos Pineda-Cortes

Centro de Investigaciones Regionales “Dr. Hideyo Noguchi”. Universidad Autónoma de Yucatán.

\section{Autor para correspondencia}

Nombre: Dr. Juan Carlos Pineda

Institución: Centro de Investigaciones Regionales "Dr. Hideyo Noguchi”

Departamento: Laboratorio de electrofisiología y biofísica

E-mail: pcortes@correo.uady.mx

Recibido: el 04 de diciembre de 2016 Aceptado para publicación: el 04 de diciembre de 2016

Copyright (C) 2016 por autores (s) y Revista Biomédica.

Este trabajo esta licenciado bajo las atribuciones de la Creative Commons (CC BY).

http://creativecommons.org/licenses/by/4.0/

(c) (i) Open Access 
Los microbios colonizan la gran mayoría de los espacios en los animales vertebrados (tanto en el exterior como en el interior del cuerpo); consecuentemente, ambos han evolucionado juntos de tal forma que se ha desarrollado una relación estrecha y compleja entre dichos vertebrados como huéspedes, y su microbiota, relación que ha influido en su propio genotipo y, lo que es más importante, en su fenotipo.

La microbiota intestinal consiste de trillones de microorganismos que representan muchas especies diferentes de bacterias y virus conocidos. De hecho, entre los mamíferos, los humanos le proporcionamos "alojamiento", mientras que, a su vez, la microbiota realiza numerosas funciones biológicas que no podemos realizar a través de nuestro propio metabolismo. Sin embargo, cuando la comunicación entre estos "órganos" y nuestros órganos se desordena, esta relación simbiótica produce el riesgo de desarrollar enfermedades (1).

De hecho, la relación de la microbiota con el sistema nervioso central (SNC) fue reconocida hace muchos años. Sin embargo, los descubrimientos sobre los mecanismos de la interacción entre el sistema inmune y el sistema nervioso en los últimos 20 años, han permitido reconocer la participación del dicha microbiota en la etiopatogenia de diversas enfermedades neurodegenerativas del sistema nervioso central (2).

Pero, ¿Cómo sucede esta interacción? La relación bidireccional entre la microbiota intestinal y el cerebro, conocida como "Eje microbiota-intestino-cerebro", sucede por varias vías aferentes o eferentes que se han implicado en este eje. La evidencia ha mostrado que la microbiota intestinal regula de forma ascendente la inflamación local y sistémica, debido a que los lipopolisacáridos (LPS) de bacterias patógenas inducen la síntesis de citoquinas proinflamatorias. La estimulación excesiva del sistema inmune innato resultante de la alteración en la flora intestinal (disbiosis intestinal) y/o el crecimiento excesivo de las bacterias intestinales junto con el aumento de la permeabilidad intestinal, pueden producir inflamación sistémica y/o del SNC. De esta forma, pueden contribuir en la generación de trastornos neurodegenerativos (3).

También, se ha mostrado que agentes ambientales e infecciosos diversos como los antibióticos, los neurotransmisores / neuromoduladores intestinales, las fibras vagales sensoriales, las citoquinas y los metabolitos esenciales, transmiten información al sistema nervioso central sobre el estado intestinal. A su vez, el eje hipotalámico-pituitario-suprarrenal, las áreas reguladoras del SNC de saciedad y los neuropéptidos liberados de las fibras nerviosas sensoriales, afectan directamente a la composición de la microbiota intestinal a través de la disponibilidad de nutrientes (3). 
Existe evidencia creciente de que estas interacciones influyen en la patogénesis de una serie de trastornos previamente considerados como exclusivamente neurodegenerativos o del ánimo, tales como la depresión, la enfermedad bipolar, los trastornos del espectro autista, el trastorno de hiperactividad con déficit de atención, la esquizofrenia, la esclerosis múltiple y la obesidad; pero que ahora se han relacionado con procesos inflamatorios producidos por bacterias o virus. Por ejemplo, se sabe que Helicobacter pylori puede existir no sólo en la mucosa gástrica, sino también en la sangre periférica, donde podría causar bacteriemia y mediante algún mecanismo contribuír a la aparición de la enfermedad de Parkinson (EP) o patologías relacionadas que preceden a los síntomas motores (4).

La EP se caracteriza por la aparición de una proteína intracelular llamada "alfa-sinucleína" que afecta a todos los niveles del eje cerebro-intestino. Tanto las evidencias clínicas como neuropatológicas, indican que los cambios neurodegenerativos en la EP están acompañados por síntomas gastrointestinales que pueden preceder o seguir el deterioro del SNC. En el caso de la forma esporádica de la EP, el proceso patológico subyacente consiste en una fase muy temprana no sintomática, seguida de un periodo prodromal, caracterizado a menudo por disfunción olfativa con desregulación autonómica, y/o trastornos del estado de ánimo y del sueño. Posteriormente inicia la fase que se acompaña de los síntomas somato-motores clásicos y deterioro del funcionamiento cognitivo. La duración de cada fase varía considerablemente de un individuo a otro. Sin embargo, en el momento del diagnóstico, cuando los pacientes han cruzado el umbral para que se manifieste la enfermedad somato-motora, el proceso patológico dentro del sistema nervioso ya está notablemente avanzado. Generalmente, la enfermedad progresa de manera caudo-rostral a través de regiones susceptibles del tronco encefálico inferior al mesencéfalo, luego llega a la corteza cerebral antigua y finalmente a todo el neocórtex. Se ha propuesto que la desregulación del eje cerebro-intestinomicrobiota puede contribuir significativamente a la patogénesis de esta enfermedad. De hecho, debido a la estrecha relación entre la disbiosis intestinal, la permeabilidad intestinal anómala y la disfunción neurológica; se ha sugerido que la modificación de la microbiota intestinal podría proporcionar una opción terapéutica prometedora para la $\mathrm{EP}(5)$ (2).

La investigación reciente también ha mostrado que la microbiota del tracto gastrointestinal está relacionada con la patogenia del Alzheimer a través del desencadenamiento de enfermedades metabólicas, y el progreso de un estado de inflamación de bajo grado (6). El arsenal terapéutico para la modulación de dicha microbiota con antibióticos o probióticos, actualmente se utiliza también como herramienta para el manejo del autismo y otros trastornos psiquiátricos o del estado de ánimo, estando ya a prueba en modelos animales. Los resultados han sido prometedores y han impulsado un 
Pineda-Cortes J

número creciente de estudios evaluando el papel de la microbiota intestinal en el desarrollo de estos trastornos (3).

\section{Referencias}

1. Cani PD, Knauf C. How gut microbes talk to organs: The role of endocrine and nervous routes. Molecular metabolism 2016 Sep; 5(9): 743-52. DOI:10.1016/j.molmet.2016.05.011

2. Scheperjans F. Can microbiota research change our understanding of neurodegenerative diseases? Neurodegenerative disease management 2016 Apr; 6(2): 81-5. DOI:10.2217/nmt-2015-0012

3. Mangiola F, Ianiro G, Franceschi F, Fagiuoli S, Gasbarrini G, Gasbarrini A. Gut microbiota in autism and mood disorders. World journal of gastroenterology 2016 Jan; 22(1): 361-8. DOI: 10.3748/wjg.v22.i1.361

4. Camci G, Oguz S. Association between Parkinson's Disease and Helicobacter Pylori. Journal of clinical neurology 2016 Apr; 12(2): 147-50. DOI: 10.3988/jen.2016.12.2.147

5. Nielsen HH, Qiu J, Friis S, Wermuth L, Ritz B. Treatment for Helicobacter pylori infection and risk of Parkinson's disease in Denmark. European journal of neurology 2012 Jun; 19(6): 864-9. DOI:10.1111/j.14681331.2011.03643.x

6. Alkasir R, Li J, Li X, Jin M, Zhu B. Human gut microbiota: the links with dementia development. Protein Cell 2016 Nov. [Epub ahead of print] DOI:10.1007/s13238-016-0338-6 